\title{
Long-term results of endovascular reconstruction for aortoiliac occlusive disease
}

\author{
Min Yang", Bihui Zhang", Guochen Niu, Ziguang Yan, Xiaoqiang Tong, Yinghua Zou \\ Department of Interventional Radiology and Vascular Surgery, Peking University First Hospital, Beijing, China
}

\#These authors contributed equally to this work.

Correspondence to: Min Yang; Yinghua Zou. Department of Interventional Radiology and Vascular Surgery, Peking University First Hospital, No. 8 Xishiku Street, Xicheng District, Beijing 100032, China. Email: dryangmin@gmail.com; yinghzou@139.com.

Background: Open surgery is the gold standard for the treatment of aortoiliac occlusive disease (AIOD). Endovascular therapy has emerged as an attractive alternative for AIOD due to its minimal invasiveness. The aims of the present study were to investigate the long-term patency of endovascular treatment and to compare the outcomes of Transatlantic Inter-Society Consensus II (TASC II) A/B and C/D lesions.

Methods: Patients with AIOD ( $\mathrm{n}=156)$ were enrolled in this retrospective cohort study. Patency rates were assessed at 12, 36, and 60 months after the procedure. Parameters for comparisons between TASC II A/B and C/D lesions included primary patency, secondary patency, freedom from target lesion revascularization (TLR), the technical success rate, the rate of complications, and risk factors for in-stent restenosis.

Results: For all patients, the technical success rate was $98.7 \%$, the complication rate was $4.5 \%$, and the mean follow-up period was 35.7 months. At 12, 36, and 60 months after the procedure, the primary patency rates were $96.5 \%, 88.3 \%$, and $80.4 \%$, respectively. The secondary patency rates were $99 \%, 96.4 \%$, and $88 \%$, respectively. The rates of freedom from TLR were $97.5 \%, 91.6 \%$, and $89.6 \%$. No significant differences were observed between $\mathrm{A} / \mathrm{B}$ and $\mathrm{C} / \mathrm{D}$ lesions in terms of primary patency $(\mathrm{P}=0.443)$, secondary patency $(\mathrm{P}=0.393)$, or freedom from TLR $(\mathrm{P}=0.481)$.

Conclusions: Endovascular reconstruction is effective and safe for AIOD, and should be the first-line treatment option for patients with TASC II A-D aortoiliac lesions.

Keywords: Aortoiliac occlusive disease (AIOD); endovascular procedures; Transatlantic Inter-Society Consensus II (TASC II)

Submitted Apr 22, 2020. Accepted for publication Nov 06, 2020.

doi: 10.21037/qims-20-599

View this article at: http://dx.doi.org/10.21037/qims-20-599

\section{Introduction}

Chronic arterial occlusive disease of the lower extremities is mainly caused by atherosclerosis, with symptoms ranging from intermittent claudication to critical limb ischemia (1). The disease is more prevalent among older people, affecting $16.9 \%$ of men and $20.5 \%$ of women aged $\geq 55$ years $(2,3)$. Approximately $30 \%$ of arterial lesions affect the aortoiliac segment, leading to aortoiliac occlusive disease (AIOD) (4).

According to the Transatlantic Inter-Society Consensus
II (TASC II), which was published in 2007 (5), the first-line therapy for $\mathrm{A} / \mathrm{B}$ lesions is endovascular therapy, while for $\mathrm{C} / \mathrm{D}$ lesions, open surgery is still the preferred approach. However, endovascular devices and techniques have advanced considerably since 2007, and endovascular therapy currently has high rates of success and few complications, even for C/D lesions (6-12). Nevertheless, a consensus regarding the use of endovascular therapy for AIOD in $\mathrm{C} /$ D lesions has not been reached (13).

In the present study, we reviewed the 13-year experience 
of the Department of Interventional Radiology and Vascular Surgery in Peking University First Hospital, in the use of endovascular reconstruction to treat AIOD. The long-term patency rates of the procedure were investigated and the outcomes of patients with TASC II A/B and C/D lesions were compared.

\section{Methods}

\section{Patient population}

This study was approved by the institutional human investigations committee of Peking University First Hospital (no. 2018043), and informed consent was obtained from all patients prior to participation. AIOD patients admitted to our department between November 2004 and May 2017 were enrolled. Patient baseline characteristics included age, sex, cardiovascular risk factors, and clinical status (14). Peripheral pulse status, ankle-brachial index (ABI) measurements, and duplex sonography results were collected. In all patients, AIOD was diagnosed by angiography or computed tomographic angiography (CTA). Lesions were classified as types A-D based on the TASC II criteria (5). Patients with stenosis $\geq 70 \%$ or total occlusion in the distal aorta, common iliac artery (CIA), or external iliac artery (EIA) were considered for endovascular treatment. All patients with AIOD in the present study received systematic stenting.

\section{Endovascular procedures}

Stents were primarily implanted in all lesions. Procedures were conducted under local anesthesia with supplemented intravenous sedation when required, and 6-7 F sheaths were chosen for artery access. Occlusions or stenoses were crossed by a 0.035 - or 0.018 -inch hydrophilic guidewire intraluminally or subintimally with a catheter. For chronic total occlusions (CTOs), antegrade recanalization was performed. In occlusive lesions of the ipsilateral CIA or EIA, the contralateral common femoral artery (CFA) was punctured using the crossover technique for an antegrade approach. For CTO of the abdominal aorta or bilateral iliac artery, left brachial arteries were also punctured to achieve antegrade recanalization. For aortic bifurcation lesions, a tri-directional approach (bilateral CFA and left brachial artery) was adopted with the pull-through technique.

In lesions involving the distal aorta and bilateral/ ipsilateral CIA, kissing balloon inflation and stenting were performed with self-expandable stents (SESs), as they are flexible and widely available in China. Balloons with a diameter of 4-6 mm were chosen for pre-dilatation. For distal aortic occlusions, stents were implanted below the renal artery origins. Post-dilation was performed if residual stenosis was $\geq 30 \%$ after stent deployment. Bare metal stents (BMS) ranging in diameter from $7-10 \mathrm{~mm}$ and in length from 40-200 $\mathrm{mm}$ were used in the endovascular procedures. Covered stents were used as a bailout method for ruptured vessels. Concomitant CFA lesions $(n=2)$ were treated with drug-coated balloon, introduced from the contralateral CFA at the same time; CFA endarterectomy was not performed.

During the procedure, heparin $(60-80 \mathrm{U} / \mathrm{kg}$ ) was used for anticoagulation. All patients were prescribed dual antiplatelet therapy (aspirin $100 \mathrm{mg} /$ day and clopidogrel $75 \mathrm{mg} /$ day) for at least 3 days before and 6 months following the procedure. After 6 months, either aspirin $(100 \mathrm{mg} /$ day $)$ or clopidogrel $(75 \mathrm{mg})$ was prescribed, depending on the patient. For patients with cardiovascular comorbidities, the strategy for antiplatelet therapy was at the doctors' discretion. Statin was prescribed for patients with dyslipidemia.

\section{Follow-up}

Follow-ups were scheduled at 1, 3, 6, and 12 months after discharge, and annually thereafter. During the visit, symptom enquiries, physical examinations, duplex ultrasound scanning, and ABI measurements were conducted. When the ABI decreased by $>20 \%$, duplex ultrasound scanning showed significant stenosis $(>50 \%)$, or the patient had severe symptoms, CTA or angiography was performed.

\section{Outcome measures and definitions}

The main outcome measure of the present study was the cumulative primary patency rates at the 12-, 36-, and 60 -month follow-ups. The secondary outcome measures were secondary patency rates, freedom from target lesion revascularization (TLR), the technical success rate, the rate of complications, and risk factors for in-stent restenosis.

Patency was defined as $<50 \%$ restenosis on CTA/ angiography or duplex ultrasound scanning. Primary patency was defined as uninterrupted patency without procedures, performed on or at the margin of the treated segment. TLR was defined as any intervention for treating restenosis or another complication of the 
culprit vessels. Complications included local infection, dissection, thromboembolism, fistulas, hematoma, acute occlusion, renal failure, stroke, and myocardial infarction. Complications were considered to be major when death, a life-threatening condition, disability, or prolonged hospitalization occurred. Other complications were defined as minor complications. Symptom improvement was defined as a decline in Rutherford category of at least 1 grade.

\section{Statistical analysis}

Statistical analyses were performed using SPSS version 20.0 (SPSS, Chicago, IL, USA) software. Continuous data are shown as means \pm standard deviations, and categorical data as counts and percentages. The baseline and immediate postoperative or follow-up measurements were compared using a paired $t$-test. The $\chi^{2}$-test and unpaired $t$-test were applied for comparisons between $\mathrm{A} / \mathrm{B}$ and $\mathrm{C} / \mathrm{D}$ lesions. Kaplan-Meier survival analysis was used to estimate primary patency, secondary patency, and freedom from TLR, and comparisons between TASC II groups were examined with the log-rank test.

Cox regression analysis was used to identify independent predictors of restenosis. Variables associated with restenosis in the univariate analysis were entered into a multivariable model $(\mathrm{P}<0.10)$. Outcomes were depicted as hazard ratios and $95 \%$ confidence intervals. For all analyses, $\mathrm{P}<0.05$ was considered to show statistical significance.

\section{Results}

\section{Patient and limb characteristics}

In total, 156 patients were included in the present study (age, $63.68 \pm 9.41$ years), of whom $134(85.9 \%)$ were male (Table 1$)$. Fifty-two (33.3\%), 30 (19.2\%), 20 (12.8\%), and 54 (34.6\%) patients conformed to the TASC II lesion classifications of A, B, C, and D, respectively. The study cohort according to TASC II classification is shown in Figure 1. Overall, $124(79.5 \%)$ patients had intermittent claudication and $32(20.5 \%)$ had critical limb ischemia, corresponding to Rutherford categories 1-3 and 4-6, respectively (Table 2).

Cardiovascular diseases and risk factors were comparable between the TASC II A/B and C/D groups; however, the former group had a lower percentage of Rutherford category 4 cases $(\mathrm{P}=0.005)$, a higher baseline $\mathrm{ABI}$ value $(\mathrm{P}<0.001)$ (Table 3), and fewer superficial femoral artery (SFA) lesions $(\mathrm{P}=0.01)$. The rate of severe calcification was similar in both groups.

\section{Acute outcomes}

The overall technical success rate of aortoiliac lesion recanalization was $98.7 \%$, with rates of $100 \%$ and $97.3 \%$ for $\mathrm{A} / \mathrm{B}$ and $\mathrm{C} / \mathrm{D}$ lesions, respectively $(\mathrm{P}=0.43)$. Technical failure in two cases was due to an inability to cross the CTO lesions. In 154 patients, 249 stents were deployed, including 238 SESs (200 GPS \& Everflex, Medtronic, Plymouth, MN, USA; 15 Innova, Boston Scientific, San Jose, CA, USA; 10 Lifestent, Bard, Tempe, AZ, USA; 5 SmartControl, Cordis Santa Clara, CA, USA; 4 MARIS, Invatec, Torbole Casaglia BS, Italy; 4 Astron, Biotronik, Berlin, Germany), 8 balloon-expandable stents (BESs) (4 Scuba, Invatec, Torbole Casaglia BS, Italy; 4 Express LD, Boston Scientific, San Jose, CA, USA), and 3 covered stents (2 Viabahn Endoprosthesis, Gore Newark, DE, USA; 1 FluencyPlus Endovascular stent graft, Bard, Tempe, AZ, USA). Of these patients, 94 received 1 stent, 33 received 2 stents, and the rest received $\geq 3$ stents.

The average number of stents used in the TASC A/ B group was $1.18 \pm 0.59$, compared with $2.05 \pm 1.25$ in the $\mathrm{C} / \mathrm{D}$ group $(\mathrm{P}<0.001)$. After the procedure, symptoms improved immediately in $94.9 \%(148 / 156)$ of patients, with no significant difference between the A/B (97.6\%) and C/D (91.9\%) groups $(\mathrm{P}=0.215)$. In both groups, the $\mathrm{ABI}$ improved significantly after the procedure (both $\mathrm{P}<0.001$; Table 3).

Complications occurred in seven patients $(4.5 \%$, major complications in four patients and minor complications in three patients), of whom one patient was in the $\mathrm{A} / \mathrm{B}$ group, and six were in the $\mathrm{C} / \mathrm{D}$ group $(\mathrm{P}=0.091$; Table 4). Three developed arterial rupture, and groin hematoma, thrombus formation at the site of treatment, myocardial infarction, and intracranial hemorrhage affected one patient each. All three arterial ruptures occurred in the C/D group; however, the difference in rupture rate between the two groups was not significant $(\mathrm{P}=0.104)$. There were two procedure-related deaths, both of which occurred in the $\mathrm{C} / \mathrm{D}$ group, with one resulting from arterial rupture and subsequent hemorrhagic shock, and the other caused by intracranial hemorrhage. The procedure-related mortality rate was $2.7 \%$ in the $\mathrm{C} / \mathrm{D}$ group and $0 \%$ in the $\mathrm{A} / \mathrm{B}$ group $(\mathrm{P}=0.223)$, equating to an overall procedure-related mortality rate of $1.3 \%$.

\section{Follow-up outcomes}

The overall follow-up rate was $81.2 \%$ (125/154), and the 
Table 1 Clinical characteristics and lesion classifications of the entire cohort and patients in the TASC II A/B or C/D group

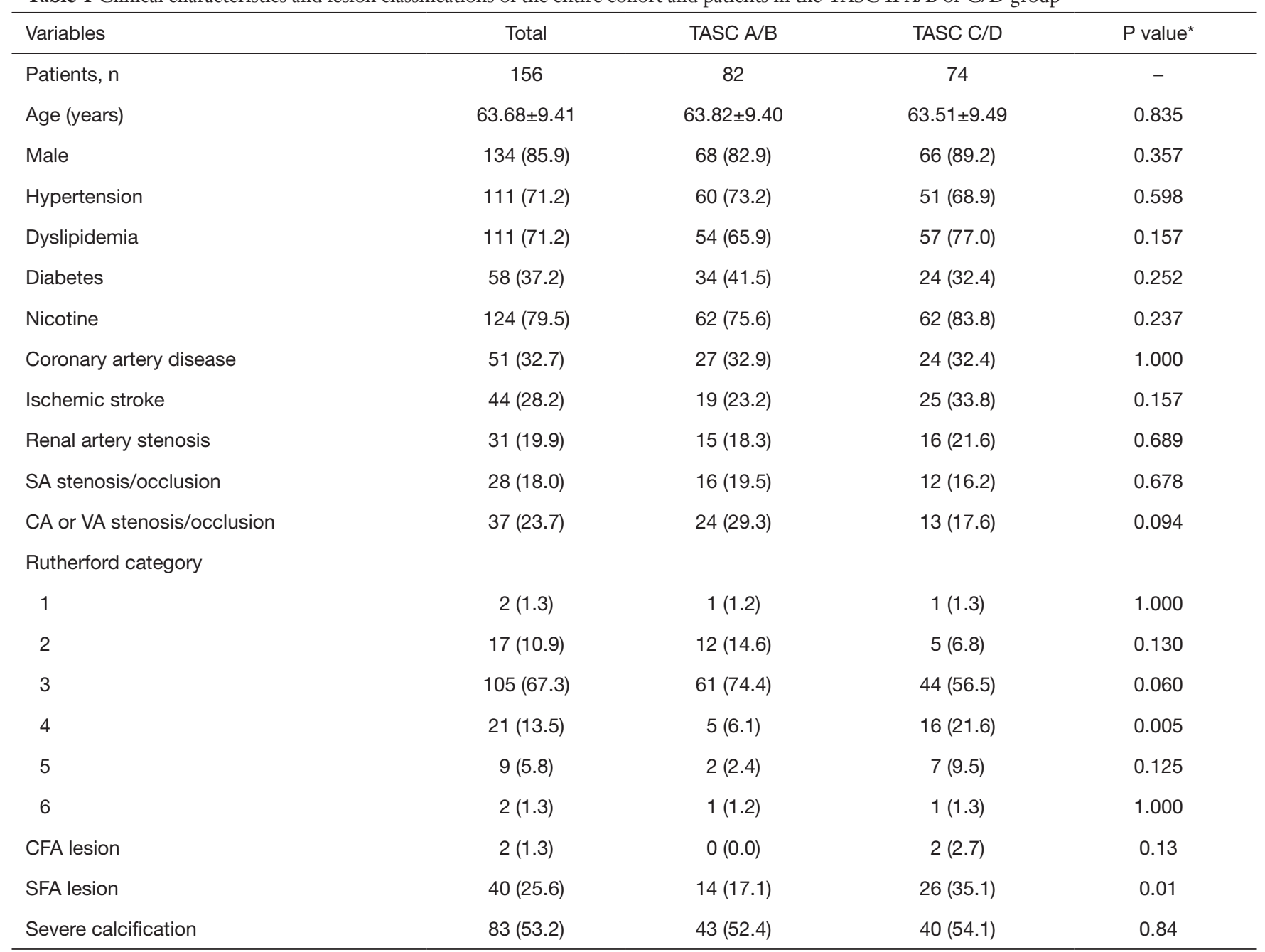

Continuous data are presented as means \pm standard deviations; categorical data are given as $\mathrm{n}(\%) ;{ }^{*}, \mathrm{P}$ value indicates significance of difference between A/B and C/D groups. TASC II, Transatlantic Inter-Society Consensus II; SA, subclavian artery; CA, carotid artery; VA, vertebral artery; CFA, common femoral artery; SFA, superficial femoral artery.

mean follow-up time was $35.7 \pm 29.1$ [5-144] months. Five patients (4\%) died during follow-up (one due to cancer, one due to chronic kidney disease, and three due to unknown reasons). The cumulative primary patency rates at 12,36 , and 60 months post treatment were $96.5 \%, 88.3 \%$, and $80.4 \%$, respectively (Figure 2). During follow-up, 6 patients $(7.31 \%)$ in the $\mathrm{A} / \mathrm{B}$ group and 10 patients $(13.5 \%)$ in the C/D group developed restenosis at the site of treatment. A total of eight patients received TLR during follow-up; of them, five patients received angioplasty, two received additional stents, and one received percutaneous mechanical thrombectomy. The cumulative rates of freedom from TLR at 12,36 , and 60 months were $97.5 \%, 91.6 \%$, and $89.6 \%$, respectively (Figure 2). The cumulative secondary patency rates at 12,36 , and 60 months after treatment were $99 \%$, $96.4 \%$, and $88 \%$, respectively (Figure 2 ).

For A/B lesions, the primary patency rates at 12,36 , and 60 months were $98.6 \%, 90.1 \%$, and $83.5 \%$, respectively (Kaplan-Meier survival analysis) (Figure 3). For C/D lesions, the primary patency rates at 12,36 , and 60 months were $93.6 \%, 85.8 \%$, and $73.5 \%$, respectively. The difference between the two groups was not significant $(\mathrm{P}=0.443)$. The rates of secondary patency and freedom from TLR were also not significantly different between the $\mathrm{A} / \mathrm{B}$ and $\mathrm{C} / \mathrm{D}$ groups ( $\mathrm{P}=0.393$ and $\mathrm{P}=0.481$, respectively).

The symptoms of $90.4 \%(114 / 125)$ of patients improved 


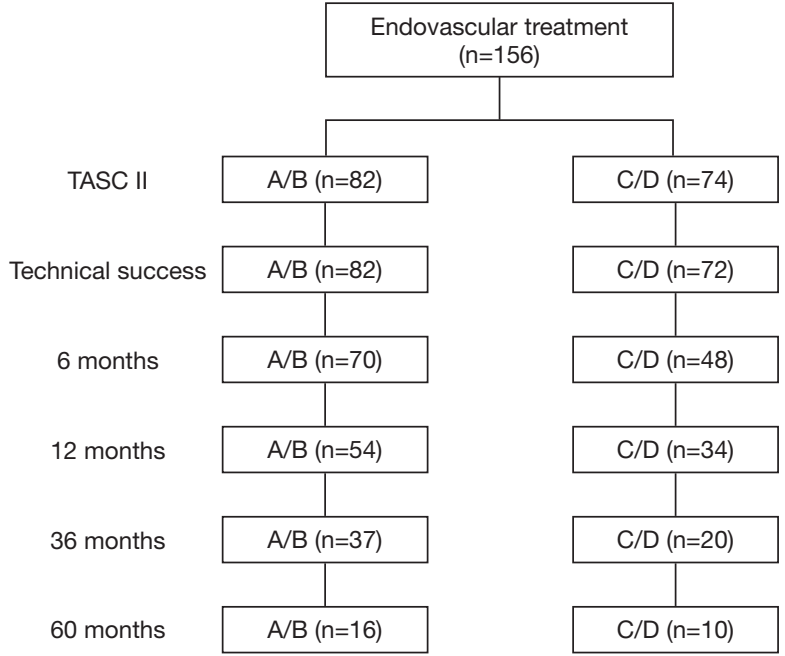

Figure 1 Flow diagram of the study cohort according to the TASC II classification. TASC II, Transatlantic Inter-Society Consensus II.

Table 2 Lesion characteristics of the cohort

\begin{tabular}{lc}
\hline Variables & Value \\
\hline Lesion length (cm) & $6.8 \pm 1.8$ \\
Bilateral lesions & $71(45.5)$ \\
Aortic lesions (with or without iliac lesions) & $16(10.3)$ \\
CTO lesions & $82(52.6)$ \\
Solitary CIA lesions & $98(50.5)$ \\
Solitary EIA lesions & $48(24.7)$ \\
Lesions of both CIA and EIA & $48(24.7)$ \\
\hline
\end{tabular}

Continuous data are presented as means \pm standard deviations; categorical data are given as $\mathrm{n}(\%)$. CTO, chronic total occlusion; CIA, common iliac artery; EIA, external iliac artery.

Table 3 ABI improvement after the procedure or at follow-up compared with baseline

\begin{tabular}{lllll}
\hline ABI & Total & TASC II A/B & TASC II C/D & $P^{*}$ \\
\hline Baseline & $0.56 \pm 0.23$ & $0.67 \pm 0.21$ & $0.47 \pm 0.20$ & $<0.001$ \\
$\begin{array}{l}\text { Post- } \\
\text { procedure }\end{array}$ & $0.92 \pm 0.27^{\star *}$ & $0.98 \pm 0.22^{\star *}$ & $0.87 \pm 0.30^{\star *}$ & 0.055 \\
Follow-up & $0.96 \pm 0.29^{\star *}$ & $0.97 \pm 0.27^{\star *}$ & $0.96 \pm 0.31^{\star *}$ & 0.916 \\
\hline
\end{tabular}

*, $P$ value indicates significance of difference between the $A /$ $B$ and $C / D$ groups; ${ }^{* *}, P<0.001$ of baseline value. $A B I$, anklebrachial index; TASC II, Transatlantic Inter-Society Consensus II.
Table 4 Intraoperative performance of patients in the TASC II A/B and C/D groups

\begin{tabular}{lccc}
\hline Variables & TASC II A/B & TASC II C/D P value \\
\hline Patients, $\mathrm{n}$ & 82 & 74 & \\
Technical failure, $\mathrm{n}(\%)$ & $0(0.0)$ & $2(2.7)$ & 0.43 \\
Complications & $1(1.2)$ & $6(8.1)$ & 0.091 \\
Total, $\mathrm{n}(\%)$ & 0 & 3 & \\
Rupture, $\mathrm{n}$ & 0 & 1 & \\
Groin hematoma, $\mathrm{n}$ & 0 & 1 & \\
$\begin{array}{l}\text { Thrombus at the treatment } \\
\text { site, } \mathrm{n}\end{array}$ & & & \\
Myocardial infarction, $\mathrm{n}$ & 1 & 0 \\
Intracranial hemorrhage, $\mathrm{n}$ & 0 & 1 \\
\hline
\end{tabular}

*, $P$ value indicates significance of difference between the $A / B$ and C/D groups. TASC II, Transatlantic Inter-Society Consensus II.

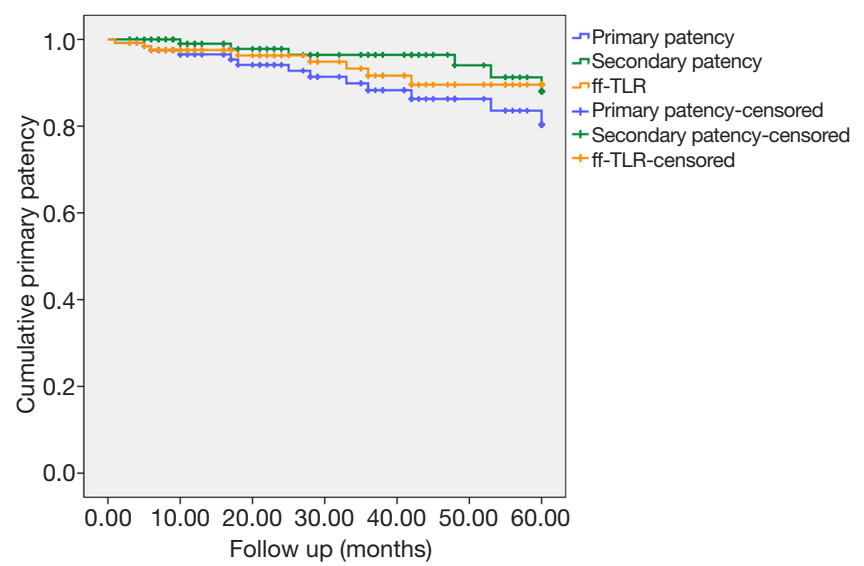

Figure 2 Kaplan-Meier analysis showing the cumulative primary patency, secondary patency, and freedom from TLR of the cohort at different follow-up times. TLR, target lesion revascularization.

during follow-up, with no significant difference between the two groups $(\mathrm{P}=0.457)$. In both the $\mathrm{A} / \mathrm{B}$ and $\mathrm{C} / \mathrm{D}$ groups, the $A B I$ values showed a significant increase relative to baseline ( $\mathrm{P}<0.001$ for both) (Table 3).

Univariate analysis determined that none of the included variables were risk factors for in-stent restenosis (all $\mathrm{P}>0.10$ ) (Table 5). Therefore, no factors were entered in the Cox multivariate analysis. 


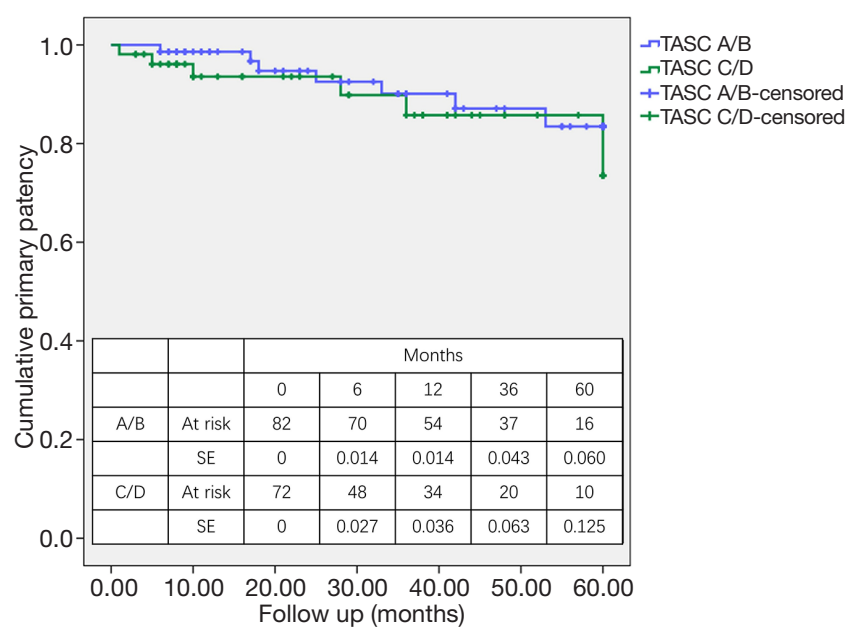

Figure 3 Kaplan-Meier analysis showing the cumulative primary patency of TASC II A/B and C/D groups at different follow-up times. For A/B lesions, the primary patency rates at 12,36 , and 60 months were $98.6 \%, 90.1 \%$, and $83.5 \%$, respectively. For C/ $\mathrm{D}$ lesions, the primary patency rates at 12,36 , and 60 months were $93.6 \%, 85.8 \%$, and $73.5 \%$, respectively $(\mathrm{P}=0.443)$. TASC II, Transatlantic Inter-Society Consensus II.

\section{Discussion}

In the present study, data of 156 AIOD patients treated with an endovascular approach were reviewed. The mean follow-up period was 35.7 [5-144] months. The overall primary patency rates at 12,36 , and 60 months after the procedure were $96.5 \%$, $88.3 \%$, and $80.4 \%$, respectively, and the cumulative freedom from TLR rates were $97.5 \%, 91.6 \%$, and $89.6 \%$, respectively. At the 60-month follow-up, no significant differences were found between the $\mathrm{A} / \mathrm{B}$ and $\mathrm{C} / \mathrm{D}$ groups in terms of the rates of primary patency, secondary patency, or freedom from TLR. The technical success rate for all patients was $98.7 \%$, while the complication rate was $4.5 \%$.

In recent years, endovascular therapy has been widely applied for AIOD. A large-scale meta-analysis of AIOD treatments determined that hospital stay, complication risk, and mortality were significantly lower for patients undergoing endovascular therapy, although those who underwent open bypass achieved higher primary patency rates (15). Similarly, a study of 4,119 AIOD patients showed that endovascular procedures resulted in lower

Table 5 Univariable analysis of risk factors for restenosis

\begin{tabular}{|c|c|c|c|c|}
\hline Factors & Standard error & $\chi^{2}$-test & Hazards ratio & $95 \%$ confidence limit for hazards ratio \\
\hline Age ( $\geq 65$ vs. <65) & 0.573 & 0.834 & 1.127 & $0.37-3.47$ \\
\hline Stroke (yes vs. no) & 0.602 & 0.858 & 0.898 & $0.28-2.93$ \\
\hline Coronary heart disease (yes vs. no) & 0.571 & 0.777 & 1.175 & $0.38-3.60$ \\
\hline Hypertension (yes vs. no) & 0.659 & 0.984 & 0.987 & $0.27-3.59$ \\
\hline Smoking (yes vs. no) & 0.659 & 0.715 & 0.786 & $0.22-2.86$ \\
\hline Dyslipidemia (yes vs. no) & 0.574 & 0.295 & 0.548 & $0.18-1.69$ \\
\hline Renal artery stenosis (yes vs. no) & 0.770 & 0.746 & 0.780 & $0.17-3.52$ \\
\hline Leriche syndrome (yes vs. no) & 0.769 & 0.854 & 1.152 & $0.26-5.20$ \\
\hline Covered stents (yes vs. no) & 12.395 & 0.807 & 0.049 & $0.00-1732843285.35$ \\
\hline Kissing stents (yes vs. no) & 0.659 & 0.425 & 1.692 & $0.47-6.16$ \\
\hline Multiple stents (yes vs. no) & 0.573 & 0.834 & 1.127 & $0.37-3.47$ \\
\hline Rutherford (4-6 vs. 1-3) & 1.042 & 0.456 & 0.460 & $0.06-3.55$ \\
\hline
\end{tabular}

TASC II, Transatlantic Inter-Society Consensus II; SFA, superficial femoral artery. 
complication rates, reduced cost, and shorter hospitalization compared with open surgery (16). Another study reported that plain old balloon angioplasty (POBA) achieved primary patency rates of only $54 \%$ and $50 \%$ at 5 and 10 years after treatment, respectively, whereas those of stenting after suboptimal POBA were $82 \%$ and $75 \%$, respectively (17). In the present study, the cumulative primary patency rates were $96.5 \%, 88.3 \%$, and $80.4 \%$ at 12,36 , and 60 months after the procedure, respectively. Further, the mean ABI and Rutherford's category were significantly improved, suggesting a satisfactory outcome.

Endovascular therapy for C/D lesions is not the preferred choice, according to TASC II (5). However, recent studies have provided evidence in recommending endovascular treatment in AIOD $(7-9,17,18)$. The Cardiovascular and Interventional Radiological Society of Europe guidelines state that endovascular therapy is the first-line option for treating type A, B, and C lesions, and in experienced centers, D (19). Furthermore, a comparison between $\mathrm{A} / \mathrm{B}$ and $\mathrm{C} / \mathrm{D}$ lesions showed that the technical success and long-term cumulative primary patency rates were not significantly different (8). Sixt et al. demonstrated that the first-line therapy strategy for AIOD should be an endovascular approach, independent of the TASC II classification (9). A novel endovascular technique, the covered endovascular reconstruction of the aortic bifurcation technique, has been applied for AIOD lesions, with reported primary patency rates of $86 \%, 84 \%$, and $82 \%$ at the 1-2-, and 3-year follow-ups, respectively (20). In the present study, the difference in primary patency rates was not significant $(\mathrm{P}=0.443)$, and the Rutherford category and $\mathrm{ABI}$ improvements were similar between the $\mathrm{A} / \mathrm{B}$ and $\mathrm{C} / \mathrm{D}$ groups.

In the present cohort, Cox analysis showed that none of the considered risk factors were related to long-term primary patency, which differed from a previously published study that indicated that female sex and residual stenosis were independent predictors of restenosis in aortoiliac bifurcation lesions (21). Another single-center study reported that the absence of anti-platelet medication was the only independent risk factor (10). The BRAVISSIMO study determined that only kissing stent configuration and obesity were predictors of restenosis (22). There is currently no consensus on the risk factors for AIOD restenosis after endovascular therapy.

In the current study, a primary stenting strategy was applied. The advantages of stent deployment over percutaneous transluminal angioplasty in terms of technical success and clinical outcomes have already been demonstrated in a previously published meta-analysis (23). However, there are also controversial reports. In the Dutch Iliac Stent Trial, 279 patients were randomly assigned to receive either direct stent placement or primary angioplasty with subsequent stent placement. No significant differences were found in technical success, or short- or long-term clinical outcomes $(24,25)$. Another study showed that selective stenting was associated with a higher clinical success rate but inferior long-term clinical success compared with primary stenting (26).

In the endovascular management of AIOD, covered stents appear to be superior compared with BMS (27-29). However, the relatively high cost of covered stents is a limiting factor for their widespread application. BESs are seemingly preferred to SESs for treating AIOD, especially in patients with lesions with severe calcification or greater recoil, due to their precise deployment and greater radial strength (30). However, there is limited evidence to support the superiority of BESs. In the only randomized controlled trial to compare BESs with SESs, the latter were found to have lower binary restenosis and lower rates of TLR compared with BESs (31). In the present study, most patients were treated with SESs, and we obtained a satisfactory outcome in both technical success and longterm patency.

Our overall complication rate was $4.5 \%$, which is in accordance with the $3-45 \%$ reported in a previous systematic review (32). The procedure-related mortality rate was $1.3 \%$, which is also within the $1.2-6.7 \%$ range reported previously (32). Furthermore, in our study, the complication rates in patients with $\mathrm{A} / \mathrm{B}$ and $\mathrm{C} / \mathrm{D}$ lesions were similar. This finding differs from that of Ichihashi et al., who found $\mathrm{C} / \mathrm{D}$ lesions $(8.8 \%)$ to have a higher complication rate than $\mathrm{A} / \mathrm{B}$ lesions $(3.1 \%, \mathrm{P}=0.014)(8)$.

The present study has two limitations. First, it was a single-center review of only endovascular treatment. Comparisons with open surgery could not be performed. Second, bias related to the sample size and loss to follow-up may limit the generalizability of the results.

\section{Conclusions}

Endovascular reconstruction for AIOD achieves good longterm primary patency, secondary patency, and freedom from TLR, with high rates of technical success and low rates of complications for both $\mathrm{A} / \mathrm{B}$ and $\mathrm{C} / \mathrm{D}$ lesions. Therefore, an endovascular-first treatment strategy should be considered 
in patients with aortoiliac disease, regardless of the current TASC classification.

\section{Acknowledgments}

Funding: The present study was supported by the Scientific Research Seed Fund of Peking University First Hospital (grant no. 2018SF023), Youth Clinical Research Project of Peking University First Hospital (grant no. 2018CR16), and Interdisciplinary Clinical Research Project of Peking University First Hospital (grant no. 2018CR33).

\section{Footnote}

Conflicts of Interest: All authors have completed the ICMJE uniform disclosure form (available at http://dx.doi. org/10.21037/qims-20-599). The authors have no conflicts of interest to declare.

Ethical Statement: The study was approved by institutional ethics/ committee of Peking University First Hospital (No. 2018043) and informed consent was taken from all the patients.

Open Access Statement: This is an Open Access article distributed in accordance with the Creative Commons Attribution-NonCommercial-NoDerivs 4.0 International License (CC BY-NC-ND 4.0), which permits the noncommercial replication and distribution of the article with the strict proviso that no changes or edits are made and the original work is properly cited (including links to both the formal publication through the relevant DOI and the license). See: https://creativecommons.org/licenses/by-ncnd/4.0\%.

\section{References}

1. Aronow WS. Management of peripheral arterial disease of the lower extremities in elderly patients. J Gerontol A Biol Sci Med Sci 2004;59:172-7.

2. Meijer WT, Hoes AW, Rutgers D, Bots ML, Hofman A, Grobbee DE. Peripheral Arterial Disease in the Elderly: The Rotterdam Study. Arterioscler Thromb Vasc Biol 1998;18:185-92.

3. Aronow WS, Ahn C, Gutstein H. Prevalence and incidence of cardiovascular disease in 1160 older men and 2464 older women in a long-term health care facility. J Gerontol A Biol Sci Med Sci 2002;57:M45-6.
4. Zeller T. Current state of endovascular treatment of femoro-popliteal artery disease. Vasc Med 2007;12:223-34.

5. Norgren L, Hiatt WR, Dormandy JA, Nehler MR, Harris KA, Fowkes FG; TASC II Working Group. Inter-Society Consensus for the Management of Peripheral Arterial Disease (TASC II). J Vasc Surg 2007;45 Suppl S:S5-67.

6. Leville CD, Kashyap VS, Clair DG, Bena JF, Lyden SP, Greenberg RK, O'Hara PJ, Sarac TP, Ouriel K. Endovascular management of iliac artery occlusions: extending treatment to TransAtlantic Inter-Society Consensus class C and D patients. J Vasc Surg 2006;43:32-9.

7. Sixt S, Alawied AK, Rastan A, Schwarzwalder U, Kleim M, Noory E, Schwarz T, Frank U, Muller C, Hauk M, Beschorner U, Nazary T, Burgelin K, Hauswald K, Leppanen O, Neumann FJ, Zeller T. Acute and longterm outcome of endovascular therapy for aortoiliac occlusive lesions stratified according to the TASC classification: a single-center experience. J Endovasc Ther 2008;15:408-16.

8. Ichihashi S, Higashiura W, Itoh H, Sakaguchi S, Nishimine K, Kichikawa K. Long-term outcomes for systematic primary stent placement in complex iliac artery occlusive disease classified according to Trans-Atlantic Inter-Society Consensus (TASC)-II. J Vasc Surg 2011;53:992-9.

9. Sixt S, Krankenberg H, Mohrle C, Kaspar M, Tubler T, Rastan A, Brechtel K, Macharzina R, Neumann FJ, Zeller T. Endovascular treatment for extensive aortoiliac artery reconstruction: a single-center experience based on 1712 interventions. J Endovasc Ther 2013;20:64-73.

10. Ye K, Lu X, Yin M, Li W, Huang Y, Huang X, Lu M, Jiang M. Midterm outcomes of stent placement for long-segment iliac artery chronic total occlusions: a retrospective evaluation in a single institution. J Vasc Interv Radiol 2013;24:859-64.

11. Gandini R, Fabiano S, Chiocchi M, Chiappa R, Simonetti G. Percutaneous treatment in iliac artery occlusion: long-term results. Cardiovasc Intervent Radiol 2008;31:1069-76.

12. Loffroy R, Edriss N, Goyault G, Chabanier A, Pernes JM, Sauguet A, Touil M, Woerly B, Pongas D, Chevallier O, Falvo N, Galland C, Midulla M, Garnier N, Guenfoudi MP, Boulin M, Aho-Gléglé S, Bost S. Percutaneous mechanical atherothrombectomy using the Rotarex®S device in peripheral artery in-stent restenosis or occlusion: a French retrospective multicenter study on 128 patients. Quant Imaging Med Surg 2020;10:283-93.

13. TASC Steering Committee, Jaff MR, White CJ, Hiatt 
WR, Fowkes GR, Dormandy J, Razavi M, Reekers J, Norgren L. An update on methods for revascularization and expansion of the TASC lesion classification to include below-the-knee arteries: a supplement to the Inter-Society Consensus for the Management of Peripheral Arterial Disease (TASC II). J Endovasc Ther 2015;22:663-77.

14. Rutherford RB, Baker JD, Ernst C, Johnston KW, Porter JM, Ahn S, Jones DN. Recommended standards for reports dealing with lower extremity ischemia: revised version. J Vasc Surg 1997;26:517-38.

15. Indes JE, Pfaff MJ, Farrokhyar F, Brown H, Hashim P, Cheung K, Sosa JA. Clinical outcomes of 5358 patients undergoing direct open bypass or endovascular treatment for aortoiliac occlusive disease: a systematic review and meta-analysis. J Endovasc Ther 2013;20:443-55.

16. Indes JE, Mandawat A, Tuggle CT, Muhs B, Sosa JA. Endovascular procedures for aorto-iliac occlusive disease are associated with superior short-term clinical and economic outcomes compared with open surgery in the inpatient population. J Vasc Surg 2010;52:1173-9, 1179.e1.

17. Koizumi A, Kumakura H, Kanai H, Araki Y, Kasama S, Sumino H, Ichikawa S, Kurabayashi M. Ten-year patency and factors causing restenosis after endovascular treatment of iliac artery lesions. Circ J 2009;73:860-6.

18. Balzer JO, Gastinger V, Ritter R, Herzog C, Mack MG, Schmitz-Rixen T, Vogl TJ. Percutaneous interventional reconstruction of the iliac arteries: primary and long-term success rate in selected TASC C and D lesions. Eur Radiol 2006;16:124-31.

19. Rossi M, Iezzi R. Cardiovascular and Interventional Radiological Society of Europe guidelines on endovascular treatment in aortoiliac arterial disease. Cardiovasc Intervent Radiol 2014;37:13-25.

20. Taeymans K, Groot Jebbink E, Holewijn S, Martens JM, Versluis M, Goverde P, Reijnen M. Three-year outcome of the covered endovascular reconstruction of the aortic bifurcation technique for aortoiliac occlusive disease. J Vasc Surg 2018;67:1438-47.

21. Aihara H, Soga Y, Iida O, Suzuki K, Tazaki J, Shintani Y, Miyashita Y. Long-term outcomes of endovascular therapy for aortoiliac bifurcation lesions in the real-AI registry. J Endovasc Ther 2014;21:25-33.

22. de Donato G, Bosiers M, Setacci F, Deloose K, Galzerano G, Verbist J, Peeters P, Setacci C. 24-month data from the BRAVISSIMO: a large-scale prospective registry on iliac stenting for TASC A \& B and TASC C \& D lesions. Ann Vasc Surg 2015;29:738-50.
23. Bosch JL, Hunink MG. Meta-analysis of the results of percutaneous transluminal angioplasty and stent placement for aortoiliac occlusive disease. Radiology 1997;204:87-96.

24. Tetteroo E, van der Graaf Y, Bosch JL, van Engelen AD, Hunink MG, Eikelboom BC, Mali WP. Randomised comparison of primary stent placement versus primary angioplasty followed by selective stent placement in patients with iliac-artery occlusive disease. Dutch Iliac Stent Trial Study Group. Lancet 1998;351:1153-9.

25. Klein WM, van der Graaf Y, Seegers J, Spithoven JH, Buskens E, van Baal JG, Buth J, Moll FL, Overtoom TT, van Sambeek MR, Mali WP. Dutch iliac stent trial: long-term results in patients randomized for primary or selective stent placement. Radiology 2006;238:734-44.

26. AbuRahma AF, Hayes JD, Flaherty SK, Peery W. Primary iliac stenting versus transluminal angioplasty with selective stenting. J Vasc Surg 2007;46:965-70.

27. Mwipatayi BP, Thomas S, Wong J, Temple SE, Vijayan V, Jackson M, Burrows SA; Covered Versus Balloon Expandable Stent Trial (COBEST) Co-investigators. A comparison of covered vs bare expandable stents for the treatment of aortoiliac occlusive disease. J Vasc Surg 2011;54:1561-70.

28. Sabri SS, Choudhri A, Orgera G, Arslan B, Turba UC, Harthun NL, Hagspiel KD, Matsumoto AH, Angle JF. Outcomes of covered kissing stent placement compared with bare metal stent placement in the treatment of atherosclerotic occlusive disease at the aortic bifurcation. J Vasc Interv Radiol 2010;21:995-1003.

29. Mwipatayi BP, Sharma S, Daneshmand A, Thomas SD, Vijayan V, Altaf N, Garbowski M, Jackson M; COBEST co-investigators. Durability of the balloon-expandable covered versus bare-metal stents in the Covered versus Balloon Expandable Stent Trial (COBEST) for the treatment of aortoiliac occlusive disease. J Vasc Surg 2016;64:83-94.e1.

30. Feldman DN, Armstrong EJ, Aronow HD, Banerjee S, Díaz-Sandoval LJ, Jaff MR, Jayasuriya S, Khan SU, Klein AJ, Parikh SA, Rosenfield K, Shishehbor MH, Swaminathan RV, White CJ. SCAI guidelines on device selection in Aorto-Iliac arterial interventions. Catheter Cardiovasc Interv 2020;96:915-29.

31. Krankenberg H, Zeller T, Ingwersen M, Schmalstieg J, Gissler HM, Nikol S, Baumgartner I, Diehm N, Nickling E, Müller-Hülsbeck S, Schmiedel R, Torsello G, Hochholzer W, Stelzner C, Brechtel K, Ito W, Kickuth R, Blessing E, Thieme M, Nakonieczny J, Nolte T, Gareis 
R, Boden H, Sixt S. Self-expanding versus balloonexpandable stents for iliac artery occlusive disease: the randomized ICE trial. JACC Cardiovasc Interv 2017;10:1694-704.

Cite this article as: Yang $M$, Zhang B, Niu G, Yan Z, Tong X, Zou Y. Long-term results of endovascular reconstruction for aortoiliac occlusive disease. Quant Imaging Med Surg 2021;11(4):1303-1312. doi: 10.21037/qims-20-599
32. Jongkind V, Akkersdijk GJ, Yeung KK, Wisselink W. A systematic review of endovascular treatment of extensive aortoiliac occlusive disease. J Vasc Surg 2010;52:1376-83. 